\title{
Holistic Biomass Transport Model for Sustainable Development of Cellulosic Biofuel
}

\author{
Rajdeep Golecha ${ }^{1}$ \\ ${ }^{1}$ Independent, Houston, USA \\ Correspondence: Rajdeep Golecha, Independent, Houston, USA. E-mail: rajdeep.golecha@gmail.com
}

Received: November 12, $2015 \quad$ Accepted: November 20, 2015 Online Published: November 30, 2015

doi:10.5539/jms.v5n4p68 URL: http://dx.doi.org/10.5539/jms.v5n4p68

\begin{abstract}
Sustainable development of the cellulosic biofuel sector will require biomass supply strategies that can minimize the cost of cellulosic biomass. While the conversion cost of cellulosic biofuel has come down significantly in the last decade, there has not been as significant change in biomass cost. Several studies have provided optimization models for minimizing biomass cost. However, most of the existing models have focused on a modelling approach to optimize a single component of biomass cost, using an integrated biomass transportation model. While separate studies have provided a model on farmer supply response that includes farmer participation and the incentives offered by biorefineries. However, there is a gap in understanding the linkage between transport cost, farmer participation and farmer incentives on biomass cost. As a result most optimization models available in literature are focused on reducing biomass transport cost. This study shows that a strong linkage exists between biomass transport cost and incentives offered to farmers. A holistic biomass supply model is developed that incorporates an integrated biomass transportation model, as well as the relationship between farmer incentives and farmer participation using data from some recent surveys. The holistic model enables a trade-off between increase in incentives and reduction in transport cost. This will help companies develop sustainable long term supply contracts between biorefineries and farmers. The study shows that biorefineries that focus on minimizing biomass cost through optimization of transport cost alone, without considering its relationships with farmer supply response will incur 15 to $20 \%$ higher biomass cost.
\end{abstract}

Keywords: corn stover, biomass cost model, cellulosic biofuels, farmer supply response, farmer incentives, biomass transport cost

\section{Introduction}

Bioenergy has attracted increasing investments and support in last decade, as a result of growing emphasis towards energy security (Percebois, 2007), and reduction in greenhouse gas (Macedo, Seabra, \& Silva, 2008). Greater emphasis is now been placed towards advancement of second generation biofuel produced from cellulosic biomass. Cellulosic biomass is primarily agricultural waste (e.g., corn stover, sugarcane bagasse, straws, etc.), forestry residues (e.g., sawdust, logging residue, etc.) or energy crops (e.g., switchgrass, elephant grass, short-rotation woody crops, etc.). For instance, the US targets to produce 76 billion litres of biofuels per year by 2022, which will require about 200 million dry tonnes of biomass annually (Biomass Research and Development Initiative (BRDI), 2008; Wilhelm et al., 2011). Corn is by far the largest source of agricultural residues for cellulosic biofuel production in the US (Turhollow et al., 2014).

Unlike corn grain that is stored and transported over a long distance economically (Attavanich et al., 2013), long distance transportation of biomass is not yet considered feasible (Axelsson et al., 2012; Jenkins et al., 1998; Preto, 2007; Marvin et al., 2012), and large scale biomass storage over a long time period is a challenge (Rentizelas, Tolis, \& Tatsiopoulos, 2009). These supply chain constraints coupled with variation in biomass supply will require biorefineries to develop supply chain strategies that minimize biomass cost through a holistic evaluation of trade-offs.

While, more than $70 \%$ agriculture waste based biomass is collection and transport (Perlack \& Turhollow, 2003; Tokgoz et al., 2005; Petrolia, 2008), the other 30\% includes grower payments for the value of removed nutrients and incentive (Turhollow et al., 2014; Perlack \& Turhollow, 2003; Tokgoz et al., 2005; Carriquiry, Du, \& Timilsina, 2011; Hettenhaus, Wooley, \& Wiselogel, 2000; Maker, 2007; Petrolia, 2008). Incentives allow farmers to generate returns on their investment, and vary with the changes in biomass market structure and regional 
supply demand dynamics (Thompson \& Tyner 2014; Petrolia, 2008; Maker, 2007). Studies focused on farmer supply response and participation have found that a strong relationship exists between farmer participation and farmer incentive (Louis, 2001; Tyndall, Berg, \& Colletti, 2011; Thompson \& Tyner, 2014).

Several studies have developed biomass cost optimization models, using an integrated biomass transportation model (Perlack \& Turhollow, 2003; Tokgoz et al., 2005; Carriquiry, Du, \& Timilsina, 2011; Hettenhaus, Wooley, \& Wiselogel, 2000; Maker, 2007; Petrolia, 2008). Recent advances include optimization of the entire biofuel supply chain (Haque et al., 2014; Lamers et al., 2015; Arnold \& Yildiz, 2015). However, there is a gap in literature in understanding the linkages between transport cost and farmer supply response. Through this study a holistic biomass supply model is developed that incorporates an integrated biomass transportation model, as well as the relationship between farmer incentives and farmer participation using data from some recent surveys (Louis, 2001; Tyndall, Berg, \& Colletti, 2011; Thompson \& Tyner, 2014). The holistic model enables a trade-offs between increase in incentives and reduction in transport cost.

The model developed through this study will further advance study on optimal supply market structures that could address variation in stover supply, and alternative feedstock availability. These will allow biorefineries to minimize biomass cost and develop optimal supply chain designs. While the model developed through this study is focused on agricultural waste (corn stover), the theoretical framework is applicable to other sources of agricultural waste based biomass.

\section{Method}

Agriculture waste based biomass costs can be divided into fixed and variable costs (Haque et al., 2014; Jenkins \& Sutherland, 2014; Griffith, Haque, \& Epplin, 2014; Thompson \& Tyner, 2014). Fixed costs are largely independent of variations in biomass yield, while variable costs vary with biomass yield:

\section{Variable Costs}

Biomass Transport Cost per unit biomass (VTC) is dependent on the biomass yield in the supply region and varies with changes in biomass yield density (Thompson \& Tyner, 2014). Incentive to farmers $\mathrm{N}$ is the farmer share of profit and varies with the changes in market structure and regional supply demand dynamics (Thompson \& Tyner, 2014; Petrolia, 2008; Maker, 2007).

\section{Fixed Costs}

Cost of biomass harvesting, biomass storage and handling are considered largely fixed as they are independent of biomass yield density (Alfonso et al., 2009; Thompson \& Tyner, 2014; Carriquiry, Du, \& Timilsina, 2011; Hettenhaus, Wooley, \& Wiselogel, 2000; Maker, 2007; Petrolia, 2008). Studies have shown that removal of agricultural waste often result in increased use of fertilizers to compensate the loss of nutrition, and to maintain soil organic carbon (SOC) (Wilhelm et al., 2011; Wilhelm et al., 2007; Graham et al., 2007). Farmers would therefore expect compensation for the biomass in proportion to the increased cost of fertilizer to supply an indifferent amount of nutrition. While nutrition replacement cost would vary with fertilizer prices (Manos et al., 2007; Huang, 2009; Srivastava, 1993), it is independent of variations in biomass yield (Wilhelm et al., 2007; Wilhelm et al., 2011; Turhollow et al., 2014; Perlack \& Turhollow, 2003; Graham et al., 2007), and hence used as fixed cost for this study for simplicity without loss of generality.

\section{Incentives}

Incentives offered to farmer for supply of the cellulosic biomass is an important component of this overall biomass strategy. Farmers expect incentives that allow them to generate returns on their investment for collection and transport of biomass (Thompson \& Tyner, 2014). As a result a strong relationship exists between farmer participation and farmer incentives, as higher incentives enable more farmers to overcome the barriers to market entry and participate (Louis, 2001; Tyndall, Berg, \& Colletti, 2011; Thompson \& Tyner, 2014). As farmer participation increases, biomass transport cost reduces, due to increased availability of biomass and the corresponding reduction in supply radius required. Biomass cost is therefore

$$
\text { Biomass Cost }=\text { Transport Cost }+ \text { Incentives }+ \text { Fixed Cost. }
$$

\subsection{Biomass Transport Cost (VTC)}

Several studies have provided a general framework for determining weighted average biomass transport cost per unit biomass (VTC) when the biorefinery is located at the centre of a circular region as shown in Figure 1 (Overend, 1982; Jenkins \& Sutherland, 2014; Walla \& Schneeberger, 2008). 
(a)

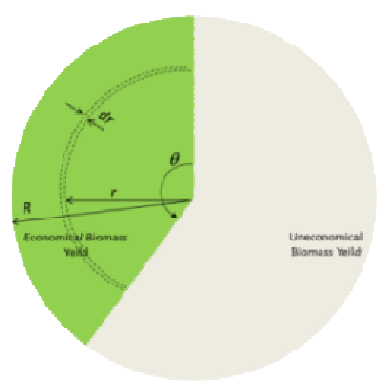

(b)

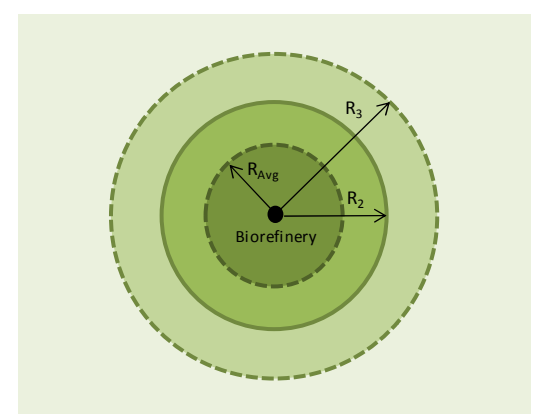

Figure 1. Biorefinery supply region to meet capacity requirements

Due to variations in biomass yield density, supply radius will vary (Figure 1b).

Using the framework from previous studies, weighted average biomass transport cost per unit biomass (VTC) is expressed as

$$
\text { Biomass Transport Cost }=\left(14.23 \tau \beta(\theta \phi M)^{-0.5} S^{0.5}\right),
$$

where:

$\theta: \quad$ region (measured in degree of the angular area) of biomass supply

$\phi$ : farmer participation rate

$\tau$ : Tortuosity Factor or ratio of actual road distance to straight line distance

$\beta$ : unit transport cost of stover $\left(\$ \mathrm{t}^{-1} \mathrm{~km}^{-1}\right)$

$S: \quad$ biorefinery capacity $\left(\mathrm{t} \mathrm{yr}^{-1}\right)$

$\boldsymbol{M}$ : biomass yield density $\left(\mathrm{t} \mathrm{ha}^{-1}\right)$

Since biomass yield density varies year to year, biomass transport cost at time $t$ (VTC), for a given biomass yield density $\mathrm{M}_{\mathrm{t}}$ is derived through manipulations of equation 2 as:

$$
\frac{\nabla V T C_{\mathrm{t}}}{V T C_{\mathrm{Avg}}}=\left(\frac{\mathbf{1}}{\sqrt{\frac{\nabla M_{\mathrm{t}}}{M_{\text {Avg }}}}+1}-\mathbf{1}\right)
$$

Using equation 3, change in biomass transport cost as a result of changes in biomass yield density is simulated in Figure 2a. Variations in biomass transport cost vs. biomass yield density are then simulated by using collectable corn stover yield density in the county of McClean, IL USA for 1990-2013 (Figure 2b).

(a)

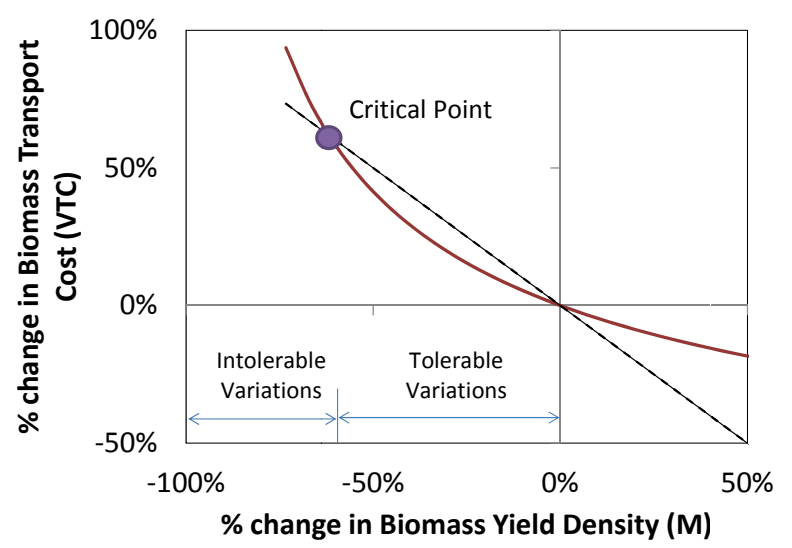

(b)

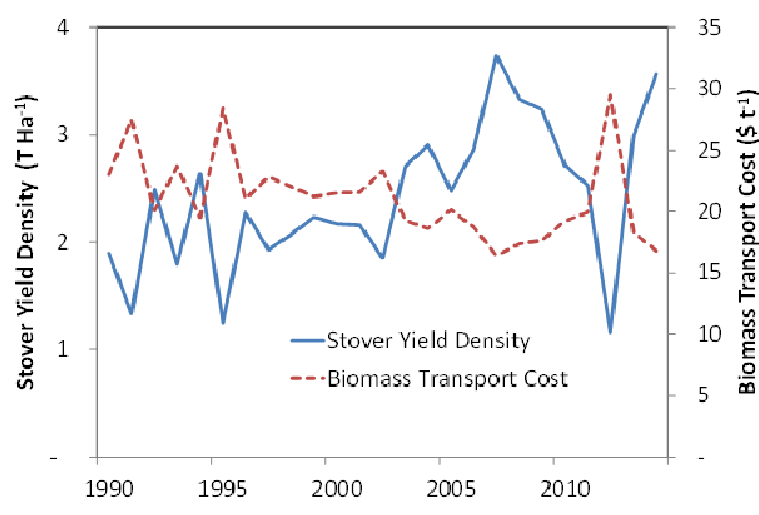

Figure 2. (a) change in biomass transport cost vs. change in biomass yield density. (b) Variations in stover yield density $\boldsymbol{M}$ vs. biomass transport cost. The solid blue line is collectable stover yield density $\boldsymbol{M}$ for the county of McClean, in Illinois US for 1990-2013 $\left(\phi=25 \%, S=500 \mathrm{kt} \mathrm{yr}^{-1}\right)$. Dotted red line is the corresponding stover transport cost. 
Using results of Figure 2b, RSD (Relative Standard Deviation) of biomass transport cost is compared with RSD of biomass yield density. It is found that variation in biomass transport cost is less than variations in yield density (Figure 3).

\section{Relative Standard Deviation}

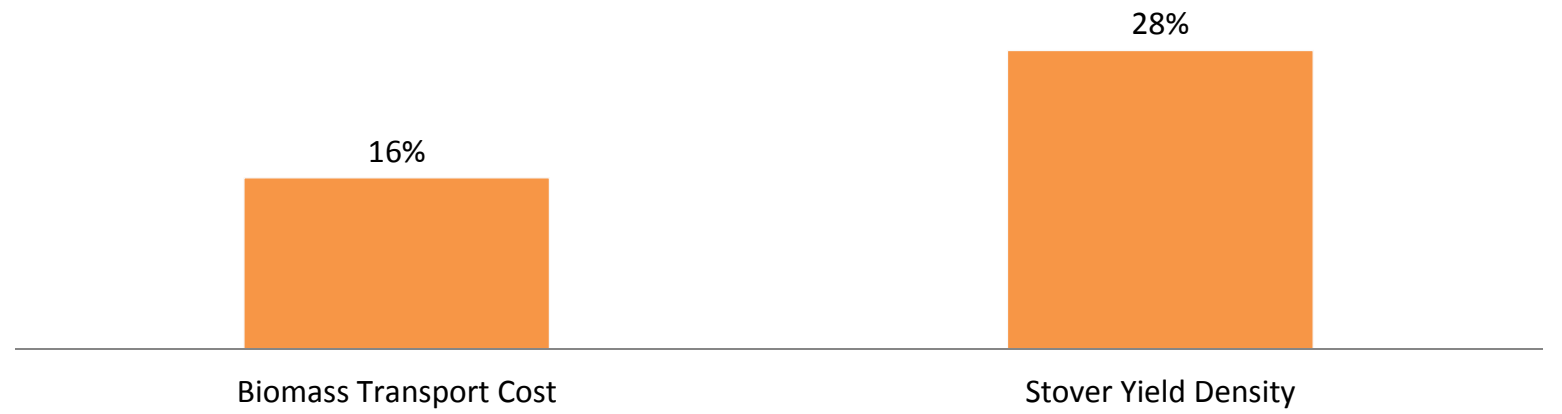

Figure 3. Relative Standard Deviation of biomass transport cost vs biomass yield density, based on stover yield density for the county of McClean, in Illinois US 1990-2013 (farmer participation = 25\%, Biorefinery Size =

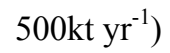

\subsection{Farmer Incentive}

Studies show that a relationship exists between farmer participation $\phi$ and farmer incentive $N$ (Louis, 2001; Tyndall, Berg, \& Colletti, 2011; Thompson \& Tyner, 2014). Higher incentives enable more farmers to overcome the barriers to entry. Because Taylor series polynomial is capable of approximating any relationship, the relation between farmer participation $\phi$ and farmer incentives $\boldsymbol{N}$ can be represented as

$$
\phi(\mathrm{N})=\phi(\boldsymbol{a})+\phi^{\prime}(\boldsymbol{a}) \frac{N}{1}+\phi^{\prime \prime}(\boldsymbol{a}) \frac{N^{2}}{2 !}+\phi^{\prime \prime \prime}(\boldsymbol{a}) \frac{N^{3}}{3 !} \ldots
$$

where $\phi$ is the farmer participation for a given incentive N. Obviously, the simplest case is when $\phi(\mathrm{N})$ can be approximated by a linear function of $N$.

The empirical relation between $\phi(\mathrm{N})$ and $N$ is then derived using data from the survey results of a study in a US corn district of Iowa (Thompson \& Tyner, 2014). Based on regression analysis of $\phi(\mathrm{N})$ and N (Figure 4), it is found that Taylor series approximation to include only the first-order derivative could explain majority variations within the elastic region. Hence, a linear approximation of equation 4 is used such as

$$
\phi=\mathrm{b} N .
$$

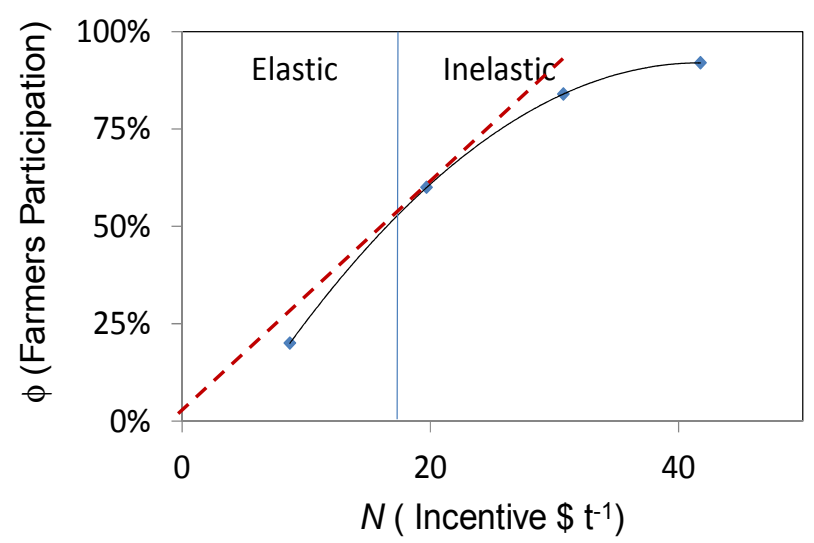

Figure 4. Farmer Participation $\phi$ vs. Incentive N, based on J. L. Thompson et al. (Thompson \& Tyner, 2014). Linear approximation of data within the elastic limit is shown by the dotted red line.

\section{Integrated Biomass Cost Model}

Using Equation 2 to 5, with some manipulations biomass cost is derived as 


$$
\text { Biomass Cost }=\underbrace{\left(\mathbf{1 4 . 2 3} \tau \beta(\theta \boldsymbol{M}(\mathrm{b} N))^{-0.5} \boldsymbol{S}^{0.5}\right)}_{A}+\underbrace{N}_{C}+\underbrace{(F C)}_{B} \text {, }
$$

where:

Term A: Transport cost

Term B: Incentive

Term C: Fixed cost

Equation 6 shows that the relationship exists between biomass transport cost and farmer incentives. To further understand the relationship between biomass transport cost, incentives, and biomass yield density, Equation 6 is simulated for different values of incentive $\boldsymbol{N}$, and biomass yield $\boldsymbol{M}$ (Figure 5).

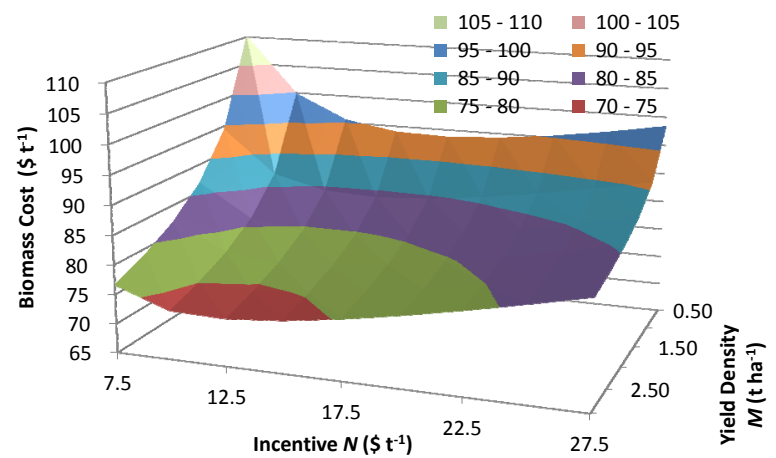

Figure 5. Biomass cost simulation at different incentive; biorefinery size $500 \mathrm{kt} \mathrm{yr}^{-1}$ and varying yield density

Figure 5 shows that for any given value of $\boldsymbol{M}, \boldsymbol{S}$ there constitutes an incentive $\boldsymbol{N}$ that results in lowest biomass cost. This point of minimal biomass cost will be reached when $(\partial B C / \partial N=0)$ and $\left(\partial^{2} B C / \partial^{2} N>0\right)$.

$$
\begin{gathered}
\frac{\partial B C}{\partial N}=-\left(14.23 \boldsymbol{\tau} \boldsymbol{b}(\boldsymbol{q} \boldsymbol{M})^{-0.5}(\boldsymbol{b} \boldsymbol{N})^{-1.5} \boldsymbol{S}^{0.5}\right) 0.5 b+(1+v s) \\
\frac{\partial^{2} B C}{\partial N^{2}}=\left(\mathbf{1 4 . 2 3} \times \mathbf{1 . 5} \boldsymbol{\tau} \boldsymbol{b}(\boldsymbol{q} \boldsymbol{M})^{-0.5} \boldsymbol{S}^{\mathbf{0 . 5}}\right) 0.5 b^{2}(\boldsymbol{b N})^{-2.5}
\end{gathered}
$$

Since $\left(\boldsymbol{M}, \boldsymbol{S}, \mathrm{b}_{1}, \tau, \beta, \theta>0\right),\left(\partial^{2} B C / \partial^{2} N>0\right)$.

Solving equations 7 and 8 , we derive the optimal incentive $N$ that results in minimum stover cost to biorefinery as

$$
N=3.69\left(\frac{(\tau \beta)^{2} S}{\theta \boldsymbol{M} \boldsymbol{b}}\right)^{0.33}
$$

Equation 9 is then simulated using 2000-2014 corn stover yield density for corn producing county of McClean in Illinois, US (Figure 6). While Figure 6 provides the optimized incentive for each year and varies due to variation in biomass yield density, biorefineries may choose to contract at a fixed incentive structure. Using a non-optimized incentive could result in a significant loss for biorefinery (Figure 6b). This is because at below optimum incentives, farmer participation is significantly reduced, resulting in significantly high transport cost, while at higher than optimal incentive the increased cost of incentive is not justified by the reduced cost of biomass transport cost. 
(a)

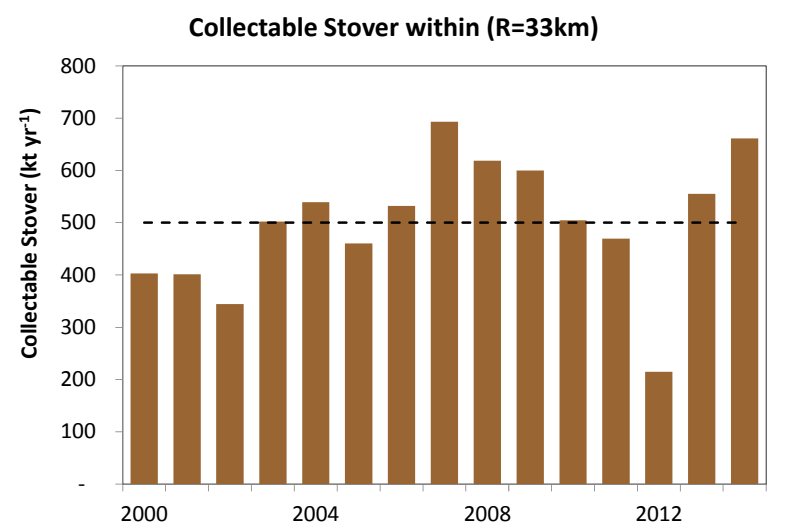

(b)

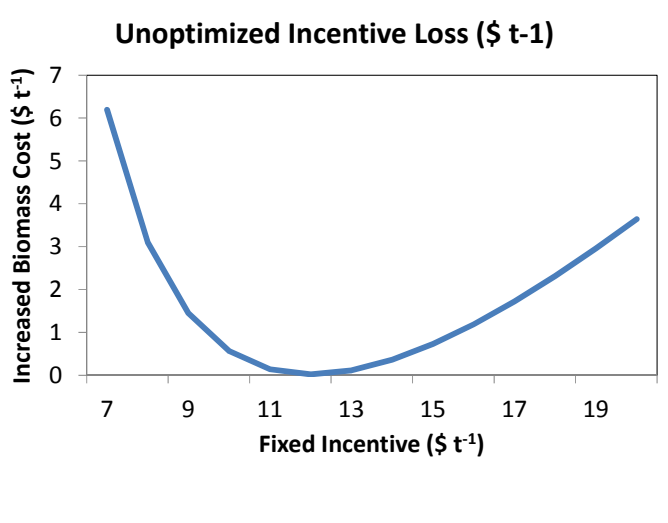

Figure 6. Simulation using 2000-2014 corn stover yield density for county of McClean in Illinois, US. (a) Corn stover availability within $33 \mathrm{~km}$ radius (b) Biorefinery loss as a result of non-optimized trade-off between transport cost and incentive

\section{Conclusions}

Biorefineries and farmers venturing into the cellulosic biofuel industry will require supply chain design that minimizes biomass cost. Previous studies have focused on using an integrated transport model for optimizing biomass cost. Other studies have provided the intricate relationship between farmer participation and the incentive offered for this biomass. This study integrated these models and a holistic biomass model is created. It is found that an intricate relationship exists between biomass transport cost and farmer incentive, and that minimal biomass cost for sustainable development of cellulosic biofuel can only be achieved by considering the trade-off between biomass transport costs the biomass incentives offered to farmers.

Biorefineries that focus on minimizing biomass transport cost alone, or only focus on minimizing incentives, without considering the intricate relationship between biomass transport cost and incentives will end up paying a 15 to $20 \%$ higher biomass cost. In developing long term supply contracts between biorefinery and farmers, managers should consider optimizing the trade-offs between biomass transport costs, incentive to farmers, farmer participation, variation in stover supply, biorefinery size, and alternative feedstock availability.

Study results for one of the major corn producing counties in US shows that supply variations in corn stover is as high as $28 \%$ based on last 15 year yield data. Biomass transport cost is a significant component of biomass cost and corresponding variations in biomass transport cost as a result of these variations is $16 \%$. Biorefineries will require market supply strategies and supply chain designs to mitigate the impact of these variations. Further studies are needed to understand the impact of biomass supply deficit as a result of these large variations and supply market structures and contracting strategies between biorefineries and farmers that can mitigate risks associated with supply variations.

\section{References}

Ag Decision Maker. (2007). Estimating a Value for Corn Stover. Iowa State University Extension, Ag Decision Maker Document FM-1698.

Alfonso, D., Perpiñá, C., Pérez-Navarro, A., Peñalvo, E., Vargas, C., \& Cárdenas, R. (2009). Methodology for Optimization of Distributed Biomass Resources Evaluation, Management and Final Energy Use. Biomass and Bioenergy, 33, 1070-1079. http://dx.doi.org/10.1016/j.biombioe.2009.04.002

Arnold, U., \& Yildiz, Ö. (2015). Economic Risk Analysis of Decentralized Renewable Energy Infrastructures-A Monte Carlo Simulation Approach. Renewable Energy, 77(May), $227-239$. http://dx.doi.org/10.1016/j.renene.2014.11.059

Attavanich, W., McCarl, B. A., Ahmedov, Z., Fuller, S. W., \& Vedenov, D. V. (2013). Effects of Climate Change on US Grain Transport. Nature Climate Change, 3, 638-643. http://dx.doi.org/10.1038/nclimate1892

Axelsson, L., Franzén, M., Ostwald, M., Berndes, G., Lakshmi, G., \& Ravindranath, N. H. (2012). Perspective: Jatropha Cultivation in Southern India: Assessing Farmers' Experiences. Biofuels, Bioproducts and Biorefining, 6, 246-256. http://dx.doi.org/10.1002/bbb 
Basil, M., Begum, M. A. A., Kamruzzaman, M., Nakou, I., \& Papathanasiou, J. (2007). Fertilizer Price Policy, the Environment and Farms Behavior. Journal of Policy Modeling, 29(1), 87-97. http://dx.doi.org/10.1016/j.jpolmod.2006.05.002

Biomass Research and Development Initiative (BRDI). (2008). Increasing Feedstock Production for Biofuels: Economic Drivers, Environmental Implications, and the Role of Research. Washington, DC. p. 146.

Carriquiry, M., Du, X. D., \& Timilsina, G. R. (2011). Second Generation Biofuels: Economics and Policies. Energy Policy, 39(7), 4222-4234. http://dx.doi.org/10.1016/j.enpol.2011.04.036

Graham, R. L., Nelson, R., Sheehan, J., Perlack, R. D., \& Wright, L. L. (2007). Current and Potential U.S. Corn Stover Supplies. Agronomy Journal, 99, 1-11. http://dx.doi.org/10.2134/agronj2005.0222

Griffith, A. P., Haque, M., \& Epplin, F. M. (2014). Cost to Produce and Deliver Cellulosic Feedstock to a Biorefinery: Switchgrass and Forage Sorghum. Applied Energy, 127, 44-54. http://dx.doi.org/10.1016/j.apenergy.2014.03.068

Haque, M., Epplin, F. M., Biermacher, J. T., Holcomb, R. B., \& Kenkel, P. L. (2014). Marginal Cost of Delivering Switchgrass Feedstock and Producing Cellulosic Ethanol at Multiple Biorefineries. Biomass and Bioenergy, 66, 308-319. http://dx.doi.org/10.1016/j.biombioe.2014.02.004

Hettenhaus, J. R., Wooley, R., \& Wiselogel, A. (2000). Biomass Commercialization Prospects in the Next 2-5 Years. National Renewable Energy Laboratory.

Huang, W. Y. (2009). Factors Contributig to the Recent Increase in U.S. Fertilizer Prices, 2002-08. USDA.

Jenkins, B. M., Baxter, L. L., Miles, T. R., \& Miles, T. R. (1998). Combustion Properties of Biomass. Fuel Processing Technology, 54, 17-46. http://dx.doi.org/10.1016/S0378-3820(97)00059-3

Jenkins, T. L., \& Sutherland, J. W. (2014). A Cost Model for Forest-Based Biofuel Production and Its Application to Optimal Facility Size Determination. Forest Policy and Economics, 38, 32-39. http://dx.doi.org/10.1016/j.forpol.2013.08.004

Lamers, P., Roni, M. S., Tumuluru, J. S., Jacobson, J. J., Cafferty, K., Hansen, J. K., ... Bals, B. (2015). Techno-Economic Analysis of Decentralized Biomass Processing Depots. Bioresource Technology, 194, 205-213. http://dx.doi.org/10.1016/j.biortech.2015.07.009

Larson, E. D., \& Marrison, C. I. (1997). Economic Scales for First-Generation Biomass-Gasifier/Gas Turbine Combined Cycles Fueled From Energy Plantations. Journal of Engineering for Gas Turbines and Power. $\mathrm{http}: / / \mathrm{dx}$.doi.org/10.1115/1.2815572

Leboreiro, J., \& Hilaly, A. K. (2011). Biomass Transportation Model and Optimum Plant Size for the Production of Ethanol. Bioresource Technology, 102(3), 2712-2723. http://dx.doi.org/10.1016/j.biortech.2010.10.144

Louis, St. (2001). Bioethanol Fuel Production Concept Study Topline Report Bioethanol Fuel Production Concept Study Topline Report. NREL/SR-510-31247; November 2001; ethanol from grain; ethanol from stover; ethanol production; farmers; stover; stover survey.

Macedo, I. C., Seabra, J., \& Silva, J. (2008). Green House Gases Emissions in the Production and Use of Ethanol from Sugarcane in Brazil: The 2005/2006 Averages and a Prediction for 2020. Biomass and Bioenergy, 32, 582-95. http://dx.doi.org/10.1016/j.biombioe.2007.12.006

Marvin, A. W., Schmidt, L. D., Benjaafar, S., Tiffany, D. G., \& Daoutidis, P. (2012). Economic Optimization of a Lignocellulosic Biomass-to-Ethanol Supply Chain. Chemical Engineering Science, 67, 68-79. http://dx.doi.org/10.1016/j.ces.2011.05.055

Nguyen, M. H., \& Prince, R. G. H. (1996). A Simple Rule for Bioenergy Conversion Plant Size Optimisation: Bioethanol from Sugar Cane and Sweet Sorghum. Biomass and Bioenergy, 10, 361-365. http://dx.doi.org/10.1016/0961-9534(96)00003-7

Overend, R. P. (1982). The Average Haul Distance and Transportation Work Factors for Biomass Delivered to a Central Plant. Biomass, 2, 75-79.

Percebois, J. (2007). Energy Vulnerability and Its Management. International Journal of Energy Sector Management. http://dx.doi.org/10.1108/17506220710738597

Perlack, R. D., \& Turhollow, A. F. (2003). Feedstock Cost Analysis of Corn Stover Residues for Further Processing. Energy, 28, 1395-1403. http://dx.doi.org/10.1016/S0360-5442(03)00123-3

Petrolia, D. R. (2008). The Economics of Harvesting and Transporting Corn Stover for Conversion to Fuel 
Ethanol: A Case Study for Minnesota. Biomass and Bioenergy, 32, $603-612$. http://dx.doi.org/10.1016/j.biombioe.2007.12.012

Preto, F. (2007). Strategies \& Techniques for Combustion of Agricultural Biomass Fuels Advantages of Energy from Biomass. Biomass. Retrieved from http://www.gtmconference.ca/site/downloads/presentations/1B3 Fernando Preto.pdf

Rentizelas, A. A., Tolis, A. J., \& Tatsiopoulos, I. P. (2009). Logistics Issues of Biomass: The Storage Problem and the Multi-Biomass Supply Chain. Renewable and Sustainable Energy Reviews. http://dx.doi.org/10.1016/j.rser.2008.01.003

Srivastava, U K. (1993). Price Elasticity of Fertilizer Demand in India: A Review. Fertilizer Pricing: Issues Related to Subsidies.

Sultana, A., \& Kumar, A. (2011). Optimal Configuration and Combination of Multiple Lignocellulosic Biomass Feedstocks Delivery to a Biorefinery. Bioresource Technology, 102(21), 9947-9956. http://dx.doi.org/10.1016/j.biortech.2011.07.119

Thompson, J. L., \& Tyner, W. E. (2014). Corn Stover for Bioenergy Production: Cost Estimates and Farmer Supply Response. Biomass and Bioenergy, 62, 166-73. http://dx.doi.org/10.1016/j.biombioe.2013.12.020

Tokgoz, S., Elobeid, A., Fabiosa, J., Hayes, D. J., Babcock, B. A., Yu, T.-H., ...Beghin, J. C. (2005). Emerging Biofuels: Outlook of Effects on U.S. Grain, Oilseed, and Livestock Markets. CARD Staff Report Series, 2600 .

Turhollow, A. F., Perlack, R. D., Eaton, L. M., Langholtz, M. H., Brandt, C. C., Downing, M. E., ... Lebow, P. (2014). The Updated Billion-Ton Resource Assessment. Biomass and Bioenergy, 70, 149-164. http://dx.doi.org/10.1016/j.biombioe.2014.09.007

Tyndall, J. C., Berg, E. J., \& Colletti, J. P. (2011). Corn Stover as a Biofuel Feedstock in Iowa's Bio-Economy: An Iowa Farmer Survey. Biomass and Bioenergy, 35, 1485-1495. http://dx.doi.org/10.1016/j.biombioe.2010.08.049

US EPA. (2013). Major Crops Grown in the United States. $A g$ 101. Retrieved from http:/www.epa.gov/agriculture/ag101/cropmajor.html

Walla, C., \& Schneeberger, W. (2008). The Optimal Size for Biogas Plants. Biomass and Bioenergy, 32, 551-557. http://dx.doi.org/10.1016/j.biombioe.2007.11.009

Wetterlund, E., Leduc, S., Dotzauer, E., \& Kindermann, G. (2012). Optimal Localisation of Biofuel Production on a European Scale. Energy, 41(1), 462-472. http://dx.doi.org/10.1016/j.energy.2012.02.051

Wilhelm, W. W., Johnson, J. M. F., Karlen, D. L., \& Lightle, D. T. (2007). Corn Stover to Sustain Soil Organic Carbon Further Constrains Biomass Supply. Agronomy Journal, 99, 1665-1667. http://dx.doi.org/10.2134/agronj2007.0150

Wilhelm, W. W., Johnson, J. M. F., Lightle, D. T., Karlen, D. L., Novak, J. M., Barbour, N. W., ...Laird, D. (2011). Vertical Distribution of Corn Stover Dry Mass Grown at Several US Locations. Bioenergy Research, 4, 11-21. http://dx.doi.org/10.1007/s12155-010-9097-z

Wright, M., \& Brown, R. C. (2007). Establishing the Optimal Sizes of Different Kinds of Biorefineries. Biofuels, Bioproducts and Biorefining. http://dx.doi.org/10.1002/bbb.25

\section{Copyrights}

Copyright for this article is retained by the author(s), with first publication rights granted to the journal.

This is an open-access article distributed under the terms and conditions of the Creative Commons Attribution license (http://creativecommons.org/licenses/by/3.0/). 